\title{
A case of normal word reading but impaired letter naming
}

\author{
Arnaud Rey ${ }^{\mathrm{a}, *}$, Niels O. Schiller ${ }^{\mathrm{b}, \mathrm{c}}$

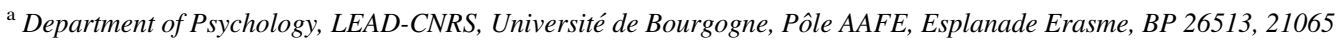 \\ Dijon Cedex, France \\ ${ }^{\mathrm{b}}$ Maastricht University, Maastricht, The Netherlands \\ ${ }^{\mathrm{c}}$ Max Planck Institute for Psycholinguistics, Nijmegen, The Netherlands
}

Received 1 September 2005; accepted 2 September 2005

\begin{abstract}
A case of a word/letter dissociation is described. The present patient has a quasi-normal word reading performance (both at the level of speed and accuracy) while he has major problems in nonword and letter reading. More specifically, he has strong difficulties in retrieving letter names but preserved abilities in letter identification. This study complements previous cases reporting a similar word/letter dissociation by focusing more specifically on word reading and letter naming latencies. The results provide new constraints for modeling the role of letter knowledge within reading processes and during reading acquisition or rehabilitation.
\end{abstract}

(c) 2005 Elsevier Ltd. All rights reserved.

Keywords: Alexia; Word reading; Letter naming

\section{Introduction}

In alphabetic writing systems, word reading is necessarily mediated by letter processing. However, the role of letter processing seems to be qualitatively different from the beginning to skilled readers. While beginning readers slowly and laboriously have to recognize each letter in a string in order to recode it phonologically, skilled readers rely mainly on global processing and access words more rapidly and directly, paying less attention to letter processing (Healy, 1994; Rey, Jacobs, Schmidt-Weigand, \& Ziegler, 1998; Rey, Ziegler, \& Jacobs, 2000).

\footnotetext{
* Tel.: +33 38039 5722; fax: +33 380395767 .

E-mail address: arnaud.rey@u-bourgogne.fr (A. Rey).
} 
Acquired deficits of reading provide information about the relation between letter and word processing in skilled reading. For example, a common feature of the so-called letter-by-letter (LBL) deficit is an impairment in letter processing (Behrmann, Plaut, \& Nelson, 1998). LBL patients have difficulties in activating letter representations and therefore have to pay more attention to each letter in order to compensate this lower letter activation (leading to the typical length effect observed in these patients). Fast letter identification appears consequently to be a mandatory process for skilled reading.

A deficit in letter processing is, however, not always associated with an impairment in word reading. In many patients presenting the so-called phonological alexia profile (Coltheart, 1996), words are read almost perfectly while the processing of nonwords is impaired. Together with the nonword reading impairment, these patients also frequently have problems in letter naming (Patterson, 2000). This word/letter dissociation has, however, received less attention compared to the word/nonword dissociation.

In the present report, we describe the case of patient $\mathrm{TH}$ who shows a particularly strong word/letter dissociation. TH reads words almost as fast and as accurately as a normal reader while he produces many errors and is much slower on nonword and letter reading. TH's letter processing is, however, preserved when he does not have to produce letter names. This clear dissociation indicates that in skilled reading, letter naming and word reading are independent processes.

\section{Case report: $\mathbf{T H}$}

At the time of testing, TH was a 63-year-old, left-handed male who had a CVA in 1982. A CT scan performed 2 years post-onset revealed an old infarct in the territory of the left middle cerebral artery. A more detailed description of his medical record can be found in a previous report (Schiller, Greenhall, Shelton, \& Caramazza, 2001). TH attended college for 1 year and worked for more than 40 years as a clerk but is now retired. He reports that he always enjoyed reading and continues to read a daily newspaper.

\subsection{Word reading}

TH's single word reading latencies were systematically tested and effects of word frequency, regularity, and consistency together with TH's ability to discriminate between words and nonwords were assessed using previously published lists of words. For all these tests, words were presented individually preceded by a fixation point for $700 \mathrm{~ms}$ followed by a blank screen for $500 \mathrm{~ms}$. Each word remained on the screen until TH's response and the next trial started after $1500 \mathrm{~ms}$. Trials including errors, hesitations, or voice key problems were excluded from further analyses. For each word list, TH's mean correct response times (RTs) and standard deviations (SD) were computed. Scores higher than 3 SD above TH's mean were considered as outliers and excluded from further analyses. All these tests were done using the Psyscope program (Cohen, MacWhinney, Flatt, \& Provost, 1993).

\subsection{Word processing}

\subsubsection{Word frequency, regularity, and consistency}

Effects of regularity, word frequency and consistency on TH's reading performance were assessed using two different lists of words. The first list (Weekes \& Coltheart, 1996) is composed 
Table 1

TH's performance on regular and irregular words (mean response times in milliseconds, number of errors, number of outliers, standard error)

\begin{tabular}{lcc}
\hline & Irregular & Regular \\
\hline Mean RT & 834 & 837 \\
Errors & 3 & 0 \\
Outliers & 0 & 0 \\
SE & 21 & 19 \\
\hline
\end{tabular}

of 40 regular and 40 irregular words. The second list (Seidenberg, Waters, Barnes, \& Tanenhaus, 1984 ) is composed of 45 high-frequency and 45 low-frequency words. Each frequency category is divided into three groups of 15 words: (1) regular and consistent words, (2) regular and inconsistent words, and (3) strange words.

TH's performance for these lists of words is presented in Tables 1 and 2. Note first that TH response times are fast and quite accurate. For the first list, his fastest and slowest correct responses were 545 and $1175 \mathrm{~ms}$. He did not produce any outliers and only three errors were recorded (two of which were lexicalizations: 'bouquet' and 'subtle' being pronounced like 'banquet' and 'shuttle'). For the second list, his fastest and slowest correct responses were 581 and $1352 \mathrm{~ms}$. He produced two outliers and three errors (one being a lexicalization: 'tile' was pronounced like 'title'). TH's reading of single words is thus overall extremely good suggesting that his direct lexical access procedure is almost unimpaired.

Regularity or consistency did not significantly affect TH's reading latencies while for frequency, he produced faster response times for high- versus low-frequency words $(t(81)=1.8$, $p=.075$ ). This pattern of results shows that TH's reading is sensitive to frequency, which is compatible with a direct lexical access procedure. Regularity or consistency did not significantly affect TH's performance indicating that he does not seem sensitive to sublexical variables.

\subsubsection{Word/nonword discrimination}

TH's ability to discriminate between words and nonwords was assessed in a lexical decision task with a list of 100 words and 100 nonwords (Stone \& Van Orden, 1993). Half of the words were of high-frequency and half of low-frequency. Half of the nonwords were pseudohomophones and the other half were orthographic controls.

TH's response times are presented in Fig. 1. TH was significantly faster for high-frequency (744 ms; one outlier) compared to low-frequency ( $845 \mathrm{~ms}$; three outliers) words, $(t(81)=4.54$, $p<.001)$. However, he was slower for orthographic controls $(879 \mathrm{~ms}$; no outlier $)$ compared to

Table 2

TH's performance high- and low-frequency words from three consistency categories: regular consistent, regular inconsistent and strange words (mean response times in milliseconds, number of errors, number of outliers, standard error)

\begin{tabular}{|c|c|c|c|c|c|c|}
\hline & \multicolumn{3}{|c|}{ High-frequency } & \multicolumn{3}{|c|}{ Low-frequency } \\
\hline & $\begin{array}{l}\text { Regular } \\
\text { consistent }\end{array}$ & $\begin{array}{l}\text { Regular } \\
\text { inconsistent }\end{array}$ & Strange & $\begin{array}{l}\text { Regular } \\
\text { consistent }\end{array}$ & $\begin{array}{l}\text { Regular } \\
\text { inconsistent }\end{array}$ & Strange \\
\hline Mean RT & 868 & 880 & 819 & 889 & 933 & 899 \\
\hline Errors & 0 & 0 & 0 & 1 & 0 & 2 \\
\hline Outliers & 0 & 0 & 0 & 0 & 1 & 1 \\
\hline SE & 33 & 39 & 25 & 27 & 42 & 43 \\
\hline
\end{tabular}




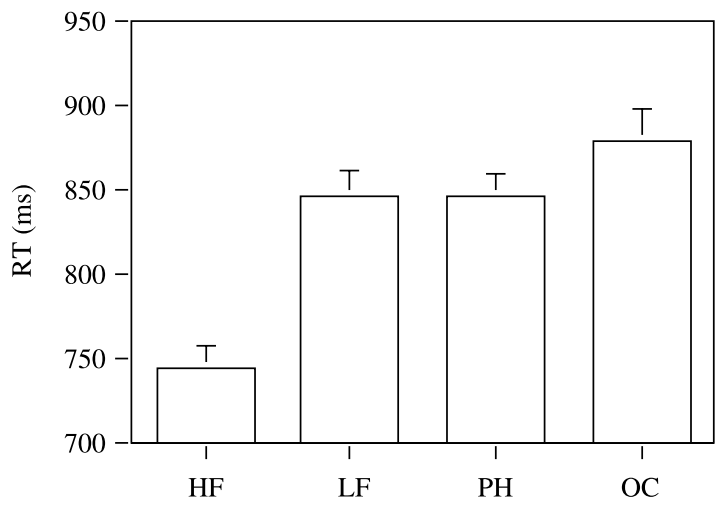

Fig. 1. TH's performance in the lexical decision task. Mean response times (RT) are plotted with standard error bars for high-frequency (HF) words, low-frequency (LF) words, pseudohomophones (PH), and orthographic controls (OC).

pseudohomophones ( $846 \mathrm{~ms}$; three outliers) but this difference did not reach significance $(t(89)=1.25, p=.21)$. For errors, TH produced 11 errors for low-frequency words and one error for high-frequency words. He also made four errors on pseudohomophones and none on orthographic controls.

\subsubsection{Word reading: summary}

TH produced only few errors in single word reading. More importantly, his reading times were close to the normal range and much faster than previously reported similar cases (Patterson, 2000). His reading performance was clearly affected by word frequency in both naming and lexical decision, indicating that his reading relies mainly on a direct lexical access procedure. In contrast, he was not affected by sublexical variables since he did not show any clear regularity, consistency, or pseudohomophone effect. This result is again consistent with the hypothesis that $\mathrm{TH}$ is reading mainly using a direct lexical access procedure.

\subsection{Nonword reading}

TH's ability to read nonwords was tested with two different lists. The first list (Hanley \& Kay, 1998 ) is composed of four groups of 10 monosyllabic nonwords, each group varying in word length (from 3 to 6 letters). The second list (Manning \& Warrington, 1995) is composed of 100 three-letter CVC nonwords divided in five groups varying on a value of wordness.

$\mathrm{TH}$ had considerable difficulties in reading nonwords from the first list and produced only $12.5 \%$ correct responses. Reading times for these correct responses were on average longer than $1 \mathrm{~s}$. TH's errors were divided into lexicalizations (32.5\%) and mispronunciations (55\%). Among the 22 mispronunciations, TH produced three phoneme omissions (e.g. bline- $>$ / baIn/), six phoneme substitutions (e.g. dut- $>/ d \Lambda f /$ ), four mixed errors (i.e. one substitution with one addition or one omission; e.g. pid- $>/ \mathrm{pimp} /$ or torf- $>/ \mathrm{tif} /$ ) and nine errors that were mostly unrelated to the target (e.g. prool- $>/ \mathrm{dr} \Lambda \mathrm{f} /$ ). Table 3 shows that his errors were evenly distributed among the four word-length categories.

Again, for the second list, $\mathrm{TH}$ produced only $20 \%$ correct responses and was much slower than for words (after excluding two correct responses produced after $5 \mathrm{~s}$, TH's mean response time was $1209 \mathrm{~ms}$ on the 18 remaining correct responses). His errors were divided in 19 
Table 3

TH's number of correct responses, lexicalization responses, and mispronunciations for the four word lists of nonwords varying in word length

\begin{tabular}{llllllll}
\hline & \multicolumn{2}{l}{ Word length } & & & \\
\cline { 2 - 5 } \cline { 5 - 7 } & 3 & 4 & 5 & 6 & & Total & $\%$ \\
\hline Correct responses & 3 & 1 & 0 & 1 & 5 & 12.5 \\
Lexicalizations & 2 & 2 & 5 & 4 & 13 & 32.5 \\
Mispronunciations & 5 & 7 & 5 & 5 & 22 & 55 \\
\hline
\end{tabular}

lexicalizations and 61 mispronunciations that were evenly distributed across the five nonword groups. Among the mispronunciations, TH produced four phoneme additions (e.g. yel- $>$ /jela/), 38 phoneme substitutions (e.g. kof- $>/ \mathrm{k} \Lambda \mathrm{f} /$ ), seven mixed errors (e.g. bom- $>$ / baIma/) and 13 errors that were mostly unrelated to the target (e.g. vij->/jef/).

To summarize, TH has a strong deficit in nonword reading. Even for three-letter nonwords, he has trouble producing a correct pronunciation. When he achieves a correct pronunciation, he needs on average almost twice as long as for words. Like most patients with a deficit in nonword reading, TH produces several lexicalizations. Finally, his mispronunciations are mainly composed of phoneme substitutions indicating that TH has troubles in the conversion of some letters into their corresponding phonemes.

\subsection{Letter processing}

TH's processing of letters was explored using three different tasks: letter naming, perceptual identification and oral spelling.

\subsubsection{Letter naming}

In the naming task, a single letter remained on the screen until $\mathrm{TH}$ produced its name. Response times were recorded for 26 letters of the alphabet, each letter appearing randomly four times in uppercase and four times in lowercase.

TH failed to retrieve letter names in 50 out of 208 trials $(24 \%)$. Twenty errors affected uppercase letters and 30 were committed on lowercase. Out of 26 letters of the alphabet, he made errors on 18 of them (A, B, L, P, Q, T, X, Z were always pronounced correctly). For some letters (D, F, and R), TH made up to five errors out of eight trials. TH reported that he "knows what the letter is but can't get it out". His response latencies were on an average higher than for words. Fig. 2 presents the distribution of response times for correct responses on letters and words (using response times from the two word naming lists). TH's naming latency for letters was on an average $1063 \mathrm{~ms}(\mathrm{SD}=248)$ while it was $859 \mathrm{~ms}(\mathrm{SD}=130)$ for words.

\subsubsection{Perceptual identification}

In the perceptual identification task, lowercase letters were presented for $33 \mathrm{~ms}$ in the middle of a computer screen. TH had to identify the letter and to enter his response using the uppercase letters of the keyboard. In order to control for the visual similarity between lowercase and uppercase letters, two experimental conditions were created. In the first condition, lowercase letters were visually similar to uppercase letters $(\mathrm{c} / \mathrm{C}, \mathrm{m} / \mathrm{M}, \mathrm{o} / \mathrm{O}, \mathrm{p} / \mathrm{P}, \mathrm{s} / \mathrm{S}, \mathrm{u} / \mathrm{U})$. In the second condition, lowercase and uppercase did not match (a/A, b/B, d/D, n/N, q/Q, r/R). There were six letters in each condition and each letter appeared seven times. Conditions 1 and 2 were also 

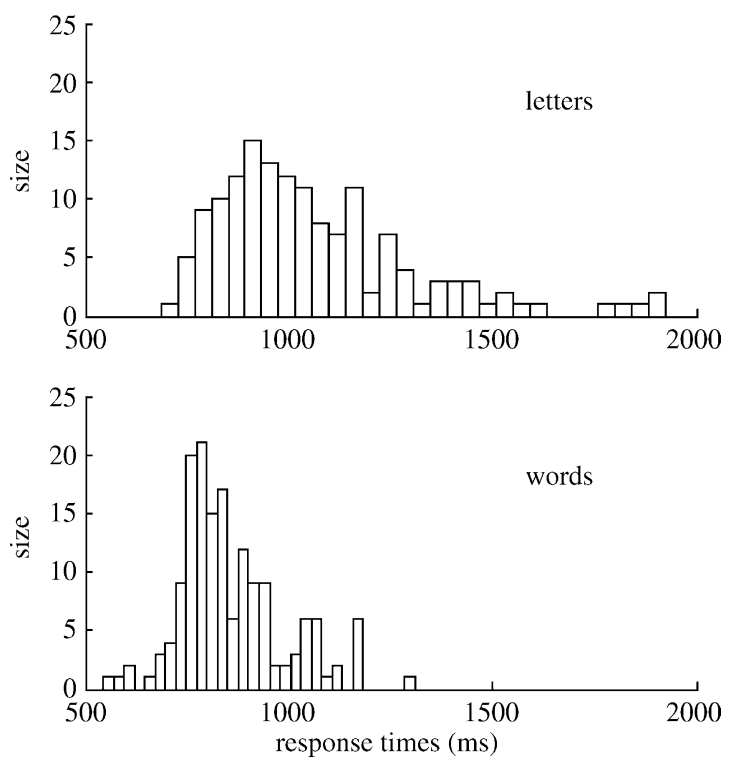

Fig. 2. Response time distributions for letters (upper panel) and words (lower panel).

matched on letter naming performance: each set of letters generated the same number of errors in the naming task (42 and 44\%, respectively, errors on an average). Finally, the remaining 14 letters of the alphabet were also presented in the experiment and were considered as fillers. Each of these letters appeared eight times.

Out of 196 trials, TH produced 175 correct responses (89.3\%). Errors were equally distributed in the two experimental conditions: there were five errors in the matching condition (condition 1) and five in the non-matching condition (condition 2). Given the very rapid presentation of the target letter $(33 \mathrm{~ms})$, this score indicates that his letter identification processes are relatively well preserved. Note also that letters were presented in lowercase and that TH had to respond by using uppercase letters. Manipulating visual similarity between lowercase and uppercase letters did not produce any difference on his performance indicating that he did not simply produce a response on the basis of a visual matching strategy. This suggests that TH's letter representations and access to these representations are overall unimpaired.

\subsubsection{Word reading and oral spelling}

In the oral spelling task, $\mathrm{TH}$ was given a list of 40 medium-to-high frequency three-letter words and had to read them aloud before producing the letter names.

TH's reading of the 40 three-letter words was perfect. However, despite this perfect performance, he only managed to produce all letter names for 11 out of the 40 words. For two words, he did not manage to name any of the letters at all . He made mistakes on two letters out of three for eight words and on (only) one letter for 19 words.

\subsubsection{Letter processing: summary}

TH's has a deficit in retrieving letter names. For some letters, his automatic access to letter names is impaired and for all letters, he needs longer to produce letter names compared to 
pronouncing words. This dissociation is particularly illustrated in the last test in which his letter naming was frequently impaired while his word reading was always perfect.

\section{Discussion}

This study reports a case of a clear dissociation between word and letter processing. More specifically, the present patient has an almost normal performance on word reading, both at the level of accuracy and speed, while his letter naming is impaired, both at the level of accuracy and speed.

TH's ability to process letters is, however, not completely impaired. Results from the perceptual identification task show that he is still able to say that lowercase 'a' and uppercase 'A' are two instances of the same letter. His visuo-spatial representations of letters are therefore preserved together with their link to abstract letter representations (Rapp \& Caramazza, 1989). His impairment does therefore not seem to affect his visual processing of letters contrary to several cases of LBL reading (Behrmann et al., 1998; but see Warrington \& Langdon, 1994). This might explain why his word reading is almost unaffected. Letter representations are indeed normally activated by visual input and this activation can spread to word representations.

TH's deficit is restricted to letter name access. For some letters, he has lost the ability to activate automatically their names indicating that knowledge of letter names can be affected independently of other reading processes. Given that his word reading is almost unimpaired, TH's performance suggests that the knowledge of letter names does not play a crucial role in skilled word reading. This result is in contrast to several developmental studies showing that the acquisition of letter names is an important step during reading development (Blatchford, Burke, Farquhar, Plewis, \& Tizard, 1987; Foulin, 2005; Muter, Hulme, Snowling \& Taylor, 1998; Treiman, 2005). It has indeed been observed that children use their knowledge of letter names in order to learn letter sounds (knowing that the name of B is /bi/ facilitates the acquisition of the B-/b/ print-to-sound association, e.g. Treiman, Tincoff, \& Richmond-Welty, 1997). The acquisition of letter sounds, mediated by letter names, initiates the establishment of print-tosound conversion processes that support phonological recoding and the progressive apparition of lexical representations (Share, 1995, 2004). It has also been shown that, before any index of phonological awareness, knowledge of letter names is the best predictor of future reading performance (Muter et al., 1998). It has even been suggested that knowledge of letter names would necessarily be developed before phonological awareness skills (Blatchford et al., 1987). The acquisition of letter names therefore appears as a fundamental step in the development of phonological conversion by facilitating the establishment of elementary print-to-sound associations and by providing visual cues that can be used to improve phonological abilities (Castles \& Coltheart, 2004).

It is interesting to note that all current computational models of word reading remain silent concerning the link between knowledge of letter names and reading processes or reading acquisition. In the dual route model (Coltheart, Rastle, Perry, Langdon, \& Ziegler, 2001), activation spreads from visual features to a level of abstract letter identities before reaching the orthographic lexicon or activating grapheme-to-phoneme conversion rules. However, in this model, the letter level has nothing to do with letter names. Similarly, the various versions of the triangle model (e.g. Harm \& Seidenberg, 1999, 2004; Plaut, McClelland, Seidenberg, \& Patterson, 1996; Seidenberg \& McClelland, 1989), which are considered as models of reading acquisition, never take into account knowledge of letter names for describing the development of phonological conversion processes. All of these theories are therefore completely explicit about the levels of representation used in reading words aloud and the absence of any mention about 
letter names suggest that this level is simply irrelevant. However, the developmental evidence indicating that knowledge of letter names plays a critical role for reading acquisition reveals a major failure of these models in accounting for the first steps in the dynamical development of the reading system. In a recent simulation study, Harm, McCandliss, and Seidenberg (2003) provide a first theoretical account of the critical role of letter-to-sound correspondences in the acquisition of reading. Although this study nicely shows that the acquisition of letter-to-sound correspondences (or elementary grapheme-to-phoneme correspondences) is a crucial step for reading development, the link with knowledge of letter names is however still missing.

Several rehabilitation studies of patients with a deep dyslexic profile have also shown that, in order to re-establish phonological conversion processes, learning letter names is a cornerstone for re-acquiring grapheme-to-phoneme associations (de Partz, 1986; Nickels, 1992). As for reading acquisition, letter naming appears therefore as a mandatory element in the architecture of print-tosound processes. It does not mean, however, that knowing letter names is a sufficient step for reacquiring phonological conversion processes. Berndt and Mitchum (1994) indeed describe a case with a similar deficit as the one presented in de Partz (1986), and although the patient was partially able to learn again letter names, she did not manage to improve her reading of nonwords due to problems in blending phonemes. Re-acquiring letter names therefore appears to be a mandatory but not sufficient step in the rehabilitation of phonological or deep dyslexic patients.

To conclude, the present case clearly indicates that knowledge of letter names can be affected while word processing is preserved. Together with developmental and rehabilitation studies, it also suggests that knowledge of letter names plays a fundamental role in the development of phonological conversion processes. The precise relation between knowledge of letter names and phonological conversion processes, still ignored by all current computational models of reading, has to be included in future theories of reading acquisition in order not only to account for the developmental evidence but, more crucially, to provide better descriptions of the rehabilitation strategies for patients with an acquired deficit of phonological or deep dyslexia.

\section{Acknowledgements}

This research was supported by a grant from the Fyssen Foundation to A. Rey. Niels O. Schiller is currently supported by the Royal Netherlands Academy of Arts and Sciences (KNAW) and grant no. 453-02-006 from the Netherlands Organization for Scientific Research (NWO). We are grateful to $\mathrm{TH}$ for his enthusiastic participation. We also thank Alfonso Caramazza for his valuable support.

\section{References}

Behrmann, M., Plaut, D. C., \& Nelson, J. (1998). A literature review and new data supporting an interactive account of letter-by-letter reading. Cognitive Neuropsychology, 15, 7-51.

Berndt, R. S., \& Mitchum, C. C. (1994). Approaches to the rehabilitation of 'phonological assembly': Elaborating the model of non-lexical reading. In M. J. Riddoch, \& G. W. Humphreys (Eds.), Cognitive neuropsychology and cognitive rehabilitation (pp. 503-526). London: Lawrence Erlbaum Associates.

Blatchford, P., Burke, J., Farquhar, C., Plewis, I., \& Tizard, B. (1987). Associations between pre-school reading related skills and later reading achievement. British Educational Research Journal, 13, 15-23.

Castles, A., \& Coltheart, M. (2004). Is there a causal link from phonological awareness to success in learning to read? Cognition, 91, 77-111. 
Cohen, J. D., MacWhinney, B., Flatt, M., \& Provost, J. (1993). PsyScope: A new graphic interactive environment for designing psychology experiments. Behavioral Research Methods, Instruments, and Computers, 25, $257-271$.

Coltheart, M. (1996). Phonological dyslexia: Past and future issues. Cognitive Neuropsychology, 13, 749-762.

Coltheart, M., Rastle, K., Perry, C., Langdon, R., \& Ziegler, J. (2001). DRC: A dual route cascaded model of visual word recognition and reading aloud. Psychological Review, 108, 204-256.

de Partz, M. P. (1986). Re-education of a deep dyslexic patient: Rationale of the methods and results. Cognitive Neuropsychology, 3, 149-177.

Foulin, J. N. (2005). Why is letter-name knowledge such a good predictor of learning to read? Reading and Writing, $18(2), 129-155$.

Hanley, J. R., \& Kay, J. (1998). Does the graphemic buffer play a role in reading? Cognitive Neuropsychology, 15, 313-318.

Harm, M. W., \& Seidenberg, M. S. (1999). Phonology, reading acquisition and dyslexia: Insights from connectionist models. Psychological Review, 106, 491-528.

Harm, M., \& Seidenberg, M. S. (2004). Computing the meanings of words in reading: Cooperative division of labor between visual and phonological processes. Psychological Review, 111, 662-720.

Harm, M. W., McCandliss, B. D., \& Seidenberg, M. S. (2003). Modeling the successes and failures of interventions for disabled readers. Scientific Studies of Reading, 7(2), 155-182.

Healy, A. F. (1994). Letter detection: A window to unitization and other cognitive processes. Psychonomic Bulletin and Review, 1, 333-344.

Manning, L., \& Warrington, E. K. (1995). The role of familiar letter combinations in phonological dyslexia. Neurocase, 1, 239-249.

Muter, V., Hulme, C., Snowling, M., \& Taylor, S. (1998). Segmentation, not rhyming, predicts early progress in learning to read. Journal of Experimental Child Psychology, 71, 3-27.

Nickels, L. A. (1992). The autocue? Self-generated phonemic cues in the treatment of a disorder of reading and naming. Cognitive Neuropsychology, 9, 155-182.

Patterson, K. (2000). Phonological alexia: The case of the singing detective. In E. Funnel (Ed.), Neuropsychology of reading (pp. 57-84). Hove, UK: Psychology Press.

Plaut, D. C., McClelland, J. L., Seidenberg, M. S., \& Patterson, K. (1996). Understanding normal and impaired reading: Computational principles in quasi-regular domains. Psychological Review, 103, 56-115.

Rapp, B. C., \& Caramazza, A. (1989). Letter processing in reading and spelling: Some dissociations. Reading and Writing, 1, 3-23.

Rey, A., Jacobs, A. M., Schmidt-Weigand, F., \& Ziegler, J. C. (1998). A phoneme effect in visual word recognition. Cognition, 68, B71-B80.

Rey, A., Ziegler, J. C., \& Jacobs, A. M. (2000). Graphemes are perceptual reading units. Cognition, 75, B1-B12.

Schiller, N. O., Greenhall, J. A., Shelton, J. R., \& Caramazza, A. (2001). Serial order effects in spelling errors: Evidence from two dysgraphic patients. Neurocase, 7, 1-14.

Seidenberg, M. S., \& McClelland, J. L. (1989). A distributed developmental model of word recognition and naming. Psychological Review, 96, 523-568.

Seidenberg, M. S., Waters, G. S., Barnes, M. A., \& Tanenhaus, M. K. (1984). When does irregular spelling or pronunciation influence word recognition? Journal of Verbal Learning and Verbal Behavior, 23, 383-404.

Share, D. L. (1995). Phonological recoding and self-teaching: Sine qua non of reading acquisition. Cognition, 55, 151-218.

Share, D. L. (2004). Orthographic learning at a glance: On the time course and developmental onset of self-teaching. Journal of Experimental Child Psychology, 87, 267-298.

Stone, G. O., \& Van Orden, G. C. (1993). Strategic control of processing in word recognition. Journal of Experimental Psychology: Human Perception and Performance, 19, 744-774.

Treiman, R. (2005). Knowledge about letters as a foundation for reading and spelling. In: P. G. Aaron \& R. M. Joshi, (Eds.), Handbook of orthography and literacy (pp. 581-599). Mahwah, NJ: Erlbaum.

Treiman, R., Tincoff, R., \& Richmond-Welty, E. (1997). Beyond zebra: Preschoolers' knowledge about letters. Applied Psycholinguistics, 18, 391-409.

Warrington, E. K., \& Langdon, D. W. (1994). Spelling dyslexia: A deficit of the visual word form. Journal of Neurology Neurosurgery and Psychiatry, 57, 211-216.

Weekes, B., \& Coltheart, M. (1996). Surface dyslexia and surface dysgraphia: Treatment studies and their theoretical implications. Cognitive Neuropsychology, 13, 277-315. 